\title{
Discussion on Model of Regional Residential Design under Traditional Culture Reservation Thought
}

\author{
Chengeng Cui \\ Shandong University of Arts, Shandong Jinan 250300 \\ Chengeng_cui@163.com
}

Keywords: Traditional culture; Retention thought; Vernacular dwelling; Design;

\begin{abstract}
Under the background of that globalization process is accelerating, the traditional culture is facing enormous challenges and new opportunities for development. How to inherit and carry forward the national excellent traditional folk residence culture have attracted the attention of Chinese scholars, increasingly. This paper studies the form of traditional dwelling, the cultural connotation of the traditional vernacular dwellings and the local customs through field survey, literature data collection, interview records, interdisciplinary research and other methods, which analyzes the protection and inheritance of traditional residence culture, which provides ideas for the protection of traditional residence culture combined with the natural environment, human environment and other factors, through the basic discussion of the forming background and evolution process of the traditional residence culture. The cultural connotation contained in the traditional residence is summarized, and the potential law of its composition is obtained, which provides the future prospects for the design of modern residential buildings and the construction of local culture.
\end{abstract}

\section{Introduction}

In the process of globalization, economy, science and technology and even culture have a certain degree of convergence phenomenon. As a complex of economy, technology and culture, the vernacular dwelling is inevitable to suffer from the impact of globalization. Although the residential industry in our country is vigorously developed, because of the monotonous and boring faces of our country residence, which is threatening and destroying the rich and colorful traditional culture in our country. In particular, the impact of traditional vernacular dwellings with regional characteristics is the most.

China's rural areas are in the transformation of modernization. Under the impact of globalization, some of the outstanding traditional things have been ignored, omitted or even disappeared, which becomes "thousands of villages look the same". That is to say, due to the lack of scientific guidance, the construction of modern rural areas has a lot of spontaneity and blindness. The villages with distinct regional characteristics in the past are gradually destroyed and abandoned by the trend of globalization. In this way, many villages have shown the same form.

In our residential creation, the creation of the inexhaustible source often comes from the colorful and multivariate traditional dwellings on the vast land. The residential works with Chinese geographical characteristics are all created by the domestic residential master after learning from the traditional local culture, which adds a thick and heavy in colors to the world culture houses. In this paper, through induction and summary of the regional residential creation methods, the corresponding improvement strategy was proposed for the modern inheritance of the regional residential building under the traditional culture reservation thought in the future.

\section{The theoretical basis of regional residential buildings}

\section{Contemporary interpretation of regionalism}

The concept of region is a concept which must be mentioned when we discuss the regional residential area. The word "region" can be interpreted as the area or scope with certain cohesion. According to the fourteenth volume of the British Encyclopedia, the word the "region" itself covers 
the same area which has the same geographical environment and social cultural environment. The similar terrain, geology, climate, rainfall, animal, plant and so on in the same region belong to homogeneous geographical environment; at the same time, the similar social population, life style, customs and cultural system in the same area belong to the homogeneity of social culture category.

The word "area" and "region" are very close in the concept. In addition, "local", "traditional", "national" in the concept often show a close relationship with the region. Each of these words has overlapping parts in its interpretation. But at the same time, it also has obvious difference. "For example, when the house is built, they will form a relatively stable place of intention with the surrounding environment, although this image also has some characteristics of gradual change and development. That is to say the production place and use place of product is the same area or region, which is called the regional". Understanding from the surface meaning, residential regionalism refers to that any residential and landscape environment is exclusive to a certain region, which could not be moved freely. So the residence has a property that is associated with each other. this property has become a commonness that exists in residential and landscape environment of the unified area. This property or commonness sense is residential regionalism of the surface meaning. But understanding from the residential regionalism from the deep sense, we can not deny that the regional is accompanied by the development of residential development process, which is one of the basic attributes that any residence has. Its explanation must define clearly from time dimension and space dimension. From the time dimension, the residential regionalism is relatively stable over a period of time, there is no instantaneous or short-term phenomenon. From the dimension of space, compared with the overall environment of the region, the residential regionalism has a certain local. For example, the majority of domestic residence will explain the meaning of regional or residential regionalism from nature, culture, technology and economy, etc.

\section{The meaning of regional residence}

Regional residential meaning has a narrow sense and broad sense. The regionalism in narrow sense refers to the response of residential works on individual environment, climate conditions and other local factors, such as the active selection of local processes local materials and construction techniques, and the local production and lifestyles have been fully considered, the local unique spirit has been translated. The regionalism in the broad sense refers to the expression way corresponding to the culture system, such as the wooden residential structure system corresponding to Han culture in Southeast Asia cultural system. Corresponding to the ancient European culture system is an epic of stone in the background of religion. Concepts that are related to regionalism are "nationality" "vernacular (dialect)" and "traditionality", and these concepts themselves are similar but not the same. 
Table 1 Residential concept about traditional culture reservation thought

\begin{tabular}{|c|c|c|}
\hline Wording & $\begin{array}{l}\text { The } \\
\text { interpretation } \\
\text { of "modern } \\
\text { Chinese } \\
\text { Dictionary" }\end{array}$ & $\begin{array}{c}\text { Semantic orientation set in the residential areas by } \\
\text { author }\end{array}$ \\
\hline Tradition & $\begin{array}{l}\text { Social factors } \\
\text { that have the } \\
\text { characteristic } \\
\text { s of } \\
\text { generation. } \\
\text { Such as } \\
\text { culture, } \\
\text { morality, } \\
\text { ideology, } \\
\text { system, etc. }\end{array}$ & $\begin{array}{l}\text { Highlight the role of the time factor. } \\
\text { The residential property caused by the generation of } \\
\text { legend. }\end{array}$ \\
\hline Region & A large area & $\begin{array}{l}\text { Highlight the role of spatial factors } \\
\text { The residential property caused by the natural } \\
\text { conditions. }\end{array}$ \\
\hline Area & $\begin{array}{l}\text { (1) a larger } \\
\text { range of } \\
\text { places; (2) } \\
\text { Not } \\
\text { independent } \\
\text { colony, trust } \\
\text { territory, etc. }\end{array}$ & Highlight the role of administrative divisions \\
\hline Nation & $\begin{array}{l}\text { Common } \\
\text { language, } \\
\text { common area, } \\
\text { Common } \\
\text { economic life } \\
\text { Community } \\
\text { of people } \\
\text { who share the } \\
\text { common } \\
\text { psychological } \\
\text { quality of } \\
\text { common } \\
\text { culture }\end{array}$ & $\begin{array}{l}\text { Highlight the role of race factor. } \\
\text { The residential property caused by the habit of belief }\end{array}$ \\
\hline $\begin{array}{l}\text { Dialect } \\
\text { (Rural) }\end{array}$ & $\begin{array}{l}\text { A language } \\
\text { that is } \\
\text { distinguished } \\
\text { from a } \\
\text { standard } \\
\text { language and } \\
\text { used only in } \\
\text { one area,........ } \\
\text { (local district) }\end{array}$ & $\begin{array}{l}\text { Highlight the role of human factors. } \\
\text { Residential property caused by the local customs and } \\
\text { practices }\end{array}$ \\
\hline
\end{tabular}

\section{From residentialism of the residential design to regional residential creative work}

Synthesizing the existing theoretical results in integrated regional concept, we can find that the residential residentialism which is the concrete expression of the existing and regional phenomena and laws in the residential works. Because it shows the existing regional results which belong to the 
philosophical category of ontology, is the re"interpretation" of the existing "results". If the regional characteristics is a constantly changing results, so the regional re-expression can be said to be an expression process which takes the original "geographical characteristics" as the basis of evolution. The purpose is to seek a sustained.

The regional residential works are regarded as a highly active residential style. This shows that due to the objective and special, the regional residential creation has a huge inclusive, "it is the product of the perfect combination of the era's creativity and the traditional experience". Theory of regional residential creation advocates seeking the different solutions based on different regional characteristics, resulting in the generation of different residential quality and style from different geographical environment, thus forming the distinctive regional creative achievements.

\section{Development review of the theory of regional architectural creation in China}

The domestic regional architecture creation starts from the inheritance and development of "Chinese inherent style", thus which is changing over the multi coexistence situation.

However, in full of the idea of "formalism standard", the exploration of regional architecture in China still shows some shortcomings. For example, compared with the modern architecture of India, China's modern buildings in energy saving, land saving and the bad weather are still the future direction of development. As theoretical achievement, the "general architectonics" is an epoch-making progress.

Regional architectural creation must be based on a dynamic system that changes with the times, which avoids ossification and immaturity, which is an important strategy we seek to keep moving forward in the colorful material and cultural background. Thus it is not difficult to find the intersection point of the context the continuation and the spirit of the times. On the one hand, regional architectural creation faces the development needs of modern architecture, on the other hand, which faces many foreign culture of impregnation, which can find the balance point. Whether to find the balance point is the key contradiction to be solved in the contemporary regional creation. The regional theory research goal is located to that replace a single area with a variety of modernity, which finds the national character and pays attention to the deep connotation which hides behind the surface with the real value.

\section{The comparison\&breaking\& restructuring of regional residential design}

Traditional local building materials mainly include soil, brick, stone, tile, wood, etc. With the introduction of the modern life and the theory of architecture, building materials in residential buildings based on the traditional materials join the concrete, brick, glass and other new materials.

\section{Definition of residential areas for materials and materials properties}

Residential building is a combination of artificial products of art and construction technology. This characteristic is embodied in the material and its concrete application. Residential materials from the visual color performance, tactile texture and comprehensive presentation texture under the action of these basic properties, combined with the technology and construction forms, specifically speaking, through collocation and combination of various materials, ultimately bring a coordinated and unified visual effects.

Due to the existence of complementary advantages of traditional material defects from the diversification of modern materials, modern materials widely used in the area such as steel, concrete and other materials, not only meet the needs of residential function, but also meet the needs of people's psychological aesthetic. With the development of modern technology, the local and the regional expression of modern materials are also the trends of the development of materials today. How to use new materials to create a modern rural residence provided with country character and regional spirit is an important topic in front of our residential masters.

Due to the long history of development, and the unique natural environment, the value of regional culture is unique. This feature is the most distinctive sign differing from other areas of residential buildings. Then, the design of residential building is bound to respect the regional cultural value of the region, in order to create the most consistent and suitable residential form. The above mentioned three types of residential form the treatment of regional cultural values on this issue each have their own performances. As shown in Table 2. 
Table 2 Comparison of regional cultural value of residence

\begin{tabular}{|c|c|c|c|}
\hline Category & $\begin{array}{l}\text { Traditional Rural } \\
\text { residence }\end{array}$ & Regional new residence & $\begin{array}{l}\text { New } \\
\text { residence }\end{array}$ \\
\hline $\begin{array}{l}\text { Whether } \\
\text { coping with } \\
\text { topography }\end{array}$ & Good deal & Better deal & Commonly \\
\hline $\begin{array}{l}\text { Whether the } \\
\text { form is } \\
\text { changeable }\end{array}$ & Yes & Yes & Commonly \\
\hline $\begin{array}{l}\text { Whether it } \\
\text { has regional } \\
\text { characteristic }\end{array}$ & Yes & Yes & No \\
\hline $\begin{array}{c}\text { The } \\
\text { relationship } \\
\text { between } \\
\text { architecture } \\
\text { and nature }\end{array}$ & $\begin{array}{l}\text { Leaning hills; Living } \\
\text { with tableland;Follow } \\
\text { and respect nature }\end{array}$ & $\begin{array}{l}\text { Can be well integrated with } \\
\text { the surrounding environment }\end{array}$ & $\begin{array}{c}\text { Can not better adapt to the } \\
\text { terrain } \\
\text { It is rejected by nature }\end{array}$ \\
\hline
\end{tabular}

By comparing we can see that the form of the new houses under blind worship of modern urban lifestyle and other subjective factors can not reflect the value of regional culture. Then, we should not blindly choose the choice of residential materials, but choose the most suitable materials for the construction of residential buildings on the basis of objective comparison analysis.

\section{The inheritance and development of local and foreign building materials}

With the development of modern technology and materials, the use of materials has changed a lot in the modern rural residential areas in Shaanxi: on the one hand, the application and the types of traditional local materials have modern variation; on the other hand, the application of local modern materials is the trend of the development of modern regional residential buildings.

Because the modern brick concrete structure has gradually become the main structural form, brick material has become the main building materials in the material of modern rural residence. In addition, it also includes stone, tile, ceramic tile, paint and other materials. The selection of building materials directly affects the economy of the building, the texture effect and other objective reality conditions. Therefore, in the choice of materials, we need to consider the cost, performance, advantages and disadvantages of technology, potential ecological value and people's aesthetic tendency and so on.

Local building materials is the spontaneous formation of people in the local architectural creation in the long-term and long-term use of building materials, such as adobe brick, tiles and so on, which has the advantages of drawn convenience, cheapness and convenient construction, and can adapt to the local climate, good comfort. However, due to the change of living habits and the injection of the new functions of modern life, the traditional building materials have a certain hindering effect in many aspects. Then, we should consider all kinds of influential factors in the selection of materials for the new residential areas, and rationally use of the traditional building materials.

Compared to the traditional residential materials, foreign materials have a great advantage in terms of physical properties and cost. But because foreign materials are not local materials in the region under the role of the material culture, there must be a lot of adaptability points in foreign building materials and their technology. We need to do a reasonable way to make them through the role of localization and then applied to the construction of local residential areas. So in the choice of building materials, we have to balance the various factors and rationally choose.

\section{The most appropriate regional residential building design materials}

For the widely used building materials, we must firstly consider the long-term use of these building materials in the region and the reasons and advantages widely accepted. Secondly, we should start with the characteristics of these materials. For the traditional building materials of restoring use, such as grass mud, straw materials, etc., we must see the potential advantages of this 
kind of building materials. Under the guidance of the concept of green, ecological and sustainable construction, these traditional building materials greatly meet their requirements. For the characteristics building materials, to highlight the regional cultural characteristics, we must do a detailed analysis to the most cultural characteristics of the local construction materials. Under the new requirements, we create a new way of expression which meets the needs of regional culture.

\section{Comparison between traditional architecture and modern construction of residence}

The traditional rural residential roof commonly used local materials are wood, small tiles, plaster, soil, grass etc. The reason is that the building materials mentioned above is not only convenient material but also is economic environmental protection;

With the introduction of modern technology and the transformation of modern life style, we find that many traditional materials are no longer economical and practical, and even some of them can not meet the basic needs of life.

Therefore, in the selection of new residential roofing materials, what we need to do is to inherit the building materials which can continue to be used in tradition and to properly introduce modern new materials which are localized. By using the method of combined use between the two under suitable conditions, the composition material of the new residential roof is selected.

\section{Conclusions}

On the basis of analyzing the special natural environment and humanistic environment of traditional culture reservation thoughts, this paper comprehensively expounds the regional characteristics of traditional residential culture from the traditional residential areas of the overall settlement to the specific residential areas, from the overall to the local, from the material to the spirit, from macro to micro. To a certain extent, the traditional dwelling culture and regional characteristics reflect the people's respect for the natural environment and the caring attitude of folk customs, reflecting the rich humanistic spirit through the residential houses. Inheriting the traditional folk residence culture which embodies the humanistic spirit, is the development direction of the future residence design. In the residential culture protection and the applied research on inheritance, we continue to explore in the hope that we can find a suitable mode of traditional residential culture protection and inheritance.

\section{Reference}

[1] Kenneth Frampton, Studies in Tectonic Culture. London:The MIT Press, 1996

[2] Lost Gardens of Sydney - " A Timely Reminder of Just How Much of Sydney"s Cultural History Has Been Lost.”, Landscape Architecture Australia, Volume 120, 2008

[3]G.R.Baryam.Masonry [M] . London: Longmans, 1914.

[4] Nilhan Vural. "Eastern Black Sea Region-A Sample of Modular Design in the Vernacular Architecture”,Building and Environment,Vol.42,No.7,2007 [3]

[5] Alexander Tzonis, "Liane Lefaivre and Bruno Stagno, Tropical Architecture, Critical Regionalism in the Age of Globalization”, Wiley-Aeademy, 2001[6] 